\title{
МЯГКАЯ СИЛА США КАК ИНСТРУМЕНТ ВНЕШНЕПОЛИТИЧЕСКОГО ВЛИЯНИЯ НА СОЮЗНОЕ ГОСУДАРСТВО
}

\author{
A. Ю. TOMA \\ Научно-культурное учреждение «Евразийское Партнерство» \\ Минск, Республика Беларусь
}

\begin{abstract}
Аннотация. В настоящее время Союзное государство, оформляющееся как самостоятельный центр силы, сталкивается с новым вызовом в виде мягкой силы США. Анализируя характер геополитических противоречий в треугольнике США - Китай - Россия можно прогнозировать новый виток противостояния, который станет серьезным вызовом для безопасности Союзного государства Беларуси и России в долгосрочной перспективе.

Статья посвящена анализу мягкой силы США в отношении Союзного государства. Автором рассмотрены понятия «мягкая сила» и «жесткая сила», а также выделены их главные отличия. В статье выявлены и проанализированы современные институты «мягкой силы», с помощью которых США могут решать целый спектр стратегических и тактических задач в отношении Союзного государства. Представлена авторская классификация данных институтов и приведены примеры влияния на Союзное государство.

В результате исследования предложены рекомендации для выстраивания эффективной системы мягкой силы в Союзном государстве Беларуси и России. Во-первых, автором рекомендовано принять Закон «Об иностранных агентах» по аналогии с тем, который действует на территории Российской Федерации. Во-вторых, автор рекомендует создавать и поддерживать собственные «институты мягкой силы», как на территории Союзного государства, так и за его пределами. В-третьих, актуально скорректировать систему финансирования институтов мягкой силы в сторону создания союзного фонда поддержи общественных инициатив с возможностью предоставлять грантовую поддержку не только юридическим, но и физическим лицам, работающим в сфере «новых медиа».
\end{abstract}

Ключевые слова: внешняя политика США; мягкая сила; неправительственные организации; Союзное государство Беларуси и России.

Образец цитирования: Тома А. Ю. Мягкая сила США как инструмент внешнеполитического влияния на союзное государство // Актуальные проблемы международных отношений и глобального развития. Минск, 2021. Вып. 9. С. 263-275. https://doi.org/10.33581/2311-9470-2021-9-263-275

Введение. Проблема изучения феномена мягкой силы США представляет значительный интерес в связи с тем, что его можно рассматривать как инструмент формирования новой геополитической 
реальности, закрепляющей доминирующее положение США. При этом важно отметить, что данный инструмент сформировался в результате осмысления стратегии ведения «холодной войны», обеспечившей не только победу в этой войне, но и обустройство однополярного мира.

Однако, как показывают события, происходящие в Афганистане в 2021 г., США становится все более трудно поддерживать свое доминирующее положение. Просчеты в собственной внешней политике дополняются активным противостоянием со стороны новых региональных центров силы (Китая и России), которые все более уверенно заявляют о собственных цивилизационных проектах и формировании многополярного мира, тем самым бросая вызов гегемонии США, что отражено в «Стратегии национальной безопасности США» [1].

В сложившейся ситуации США стремятся, с одной стороны укрепить собственные позиции через ряд внешнеполитических инициатив (AUKUS, «Транстихоокеанское партнерство»), с другой стороны, не допустить формирования геополитических проектов, которые будут способны бросить вызов доминирующему положению США. Одним из таких потенциальных проектов выступает Союзное государство Беларуси и России.

Актуальность темы статьи обусловлена тем, что после утверждения союзных программ и военной доктрины Союзного государства перед Беларусью и Россией встает вопрос о совместном ответе на общие вызовы, одним из которых выступает внешнеполитическое влияние США. В условиях военно-стратегического паритета и наличия у России ядерной триады, основной упор со стороны США по противодействию Союзному государству будет осуществлен на «институты мягкой силы», которые за последнее десятилетие доказали свою эффективность.

Цель данной статьи - проанализировать мягкую силу США в отношении Союзного государства, выявить проблемы и предложить рекомендации для выстраивания собственной эффективной системы мягкой силы.

Методы исследования. При написании статьи были использованы общенаучные и частные методы научного исследования. Эмпирический метод использовался для мониторинга СМК и Интернетпорталов по теме исследования. Активно применялся метод контентанализа, посредством которого были выявлены «институты мягкой силы США», оказывающие влияние на Союзное государство. Метод 
сравнения позволил сопоставить «мягкую силу» и «жесткую силу», тем самым выделив их отличительные черты.

Обзор литературы по теме. Главными источниками для анализа проблематики послужили работы, посвященные теории «мягкой силы», их роли и места во внешней политике государства. Среди них можно назвать научные работы Джозефа Найя «Bound to Lead: The Changing Nature of American Power» и «Soft Power. The Means to Success in World Politics». На основе работы П. Швейцера «Победа. Роль тайной стратегии администрации США в распаде Советского Союза и социалистического лагеря», в которой раскрывается стратегия США в отношении СССР, были выявлены «институты мягкой силы США» во времена «холодной войны». В работе также были использованы труды, в которых проводится обзор различных концепций, связанных с «мягкой силой». В частности, была использована работа Н.В. Бурлиновой «Курс общественного дипломата». Материалом исследования послужила «Стратегия национальной безопасности США», где наглядно прослеживается юридическая составляющая в применении «мягкой силы» для решения внешнеполитических задач.

Результаты исследования. В научное употребление термин «мягкая сила» ввел американский ученый Джозеф Най в начале 90-х гг. XX в. Под мягкой силой он понимал «способность добиваться от других желаемого результата не столько с помощью принуждения и оказания давления (военного, экономического, политического), сколько с помощью убеждения и привлечения на свою сторону зарубежной аудитории» [2].

В своих исследованиях Джозеф Най разделил мощь государства на две большие составляющие: «жесткую силу» («hard power») и «мягкую силу» («soft power») [3]. «Жесткая сила» включает в себя совокупную политическую, экономическую и военную мощь государства. К ней Джозеф Най относит различные инструменты принуждения в международных отношениях: применение вооруженных сил, публичную угрозу их применения, экономические санкции, персональные санкции в отношении отдельных должностных лиц и ряд иных мер принуждения.

В свою очередь, к «мягкой силе» Джозеф Най относит привлекательность государства (культура, история, идеология и т.д.), его достижения (производимые товары массового потребления, научнотехнические изобретения и т.д.) и внешнеполитические акции, кото- 
рые направлены на формирование благоприятного имиджа государства за рубежом.

На основании проведенного анализа научных работ Джозефа Найя нами выделено два главных отличия «мягкой силы» от «жесткой силы». Первое отличие состоит в том, что «жесткая сила» характеризуется прямым влиянием на другое государство (объект воздействия), «мягкая сила» - косвенным. Если задача «жесткой силы» принудить другое государство к выполнению определенных требований, то задача «мягкой силы» - сформировать желание со стороны государства, на которое оказывается воздействие, сделать то, чего желает государство, которое оказывает воздействие.

Второе отличие «мягкой силы» от «жесткой силы» заключается в количестве времени, необходимом для достижения результата. «Мягкая сила» ориентирована на долгосрочное воздействие на другое государство. Для достижения необходимого результата могут тратиться десятилетия, однако и последствия воздействия «мягкой силы» зачастую сохраняются намного дольше, чем от применения «жесткой силы». В 2000-х гг. концепция «мягкой силы» была доработана американским политологом Джозефом Найем в сотрудничестве с бывшим заместителем госсекретаря США Ричардом Армитиджем и представлена в обновленном виде, как концепция «умной силы» (smart power), которая представляет собой гибрид «мягкой силы» и «жесткой силы» [4].

К настоящему времени помимо концепций «мягкой» и «умной силы» имеется целый ряд концепций, призванных обеспечить США глобальное доминирование в мире с помощью «гибких» методов внешнеполитического воздействия: «концепция «Культурного империализма» (глобального доминирования ценностей одной страны, навязанное через систему образования), концепция «Американизации» (распространения идеалов и стандартов американской жизни), концепция «Взаимного культурного обмена» («переноса культур»), концепция «Национального брендинга» [2]. Эксперт РСМД Н. Бурлинова в своей работе отмечает, что «точная трактовка этих понятий пока не зафиксирована на официальном уровне, так же как не оформились эти определения в экспертной среде... каждый по-своему трактует эти понятия, не говоря уже о представлениях государственного аппарата и общественных деятелей» [2].

Причина отсутствия точных трактовок вышеназванных концепций, на наш взгляд, лежит в том, что исследователи, с одной стороны, 
не смогли посмотреть на все эти концепции как на внешние проявления «политической власти», с другой стороны, связать ее с западной геополитикой, направленной на установление мировой гегемонии через «институты мягкой силы».

Вводя в оборот термин «институт мягкой силы», Джозеф Най не стал раскрывать его содержание. По нашему мнению, это было сделано для того, чтобы вся терминология в его исследованиях была «политкорректной» и никак не ассоциировалась с такими атрибутами «холодной войны» как ЦРУ, секретные операции, подрывная деятельность, цветные революции, агентурная сеть и пр. Мы же будем исходить из того, что современные «институты мягкой силы» вряд ли начали создаваться заново, а, скорее всего, стали продолжением тех институтов, которые обеспечили победу США в холодной войне, и, следовательно, подтвердили свою эффективность в формировании новой геополитической реальности.

В этой связи мы обратимся к исследованиям Петера Швейцера, который сразу после окончания «холодной войны» опубликовал достаточно известную работу «Победа. Роль тайной стратегии Администрации США в распаде Советского Союза и Социалистического лагеря» [5]. В ней раскрывается роль ключевых «институтов мягкой силы», обеспечивших США победу в «холодной войне». Дополнив эту информацию другими источниками, мы получаем следующий состав «институтов мягкой силы», которые вели свою деятельность в период «холодной войны» [6]:

внешнеполитические ведомства и спецслужбы США (и других стран НАТО), осуществляющие разведку, дипломатическую и подрывную деятельность в СССР и в дружественных ему странах;

- научная элита и выпускники из Гарварда, Принстона, Йелля и других университетов, формировавшие «стратегию наступления на экономическом, геополитическом и психологическом фронте, имевших своей целью подрыв и ослабление советского могущества» [6];

международные медиа организации: радиостанция «Голос Америки» (начала вещание на языках народов СССР с 1947 г.), радиостанция «Национального комитета Свободной Европы» (начала вещания на страны социалистического лагеря в Европе с территории Западной Германии с 1950 г.), международная радиокомпания «Радио Свободная Европа/Радио Свобода» и др.

международные неправительственные организации, созданные в сотрудничестве с партнерами по НАТО: «Международная Ам- 
нистия» (действовала на территории СССР с 1974 по 1983 гг.), Хьюман Райтс Вотч (основана в 1978 г. как частная американская неправительственная организация для мониторинга соблюдения СССР Хельсинкских соглашений).

Анализируя характер современных внешнеполитических процессов, можно предположить, что все вышеназванные институты не были утилизированы как рудименты «холодной войны», а наоборот были «обновлены» и дополнены целым рядом различных организаций. Среди них можно выделить так называемые фабрики мысли или «мозговые центры» и медиа-холдинги США. Однако наиболее весомую роль в осуществлении мягкой силы США на современном этапе играют неправительственные организации (НПО) и фонды.

По данным Госдепартамента США, более 15 тыс. американских НПО действуют на международной арене и напрямую либо косвенно осуществляют деятельность по продвижению национальных интересов и содействуют созданию положительного образа США в других странах [7, с. 44]. На основании проведенного исследования Центра стратегических оценок и прогнозов (Российская Федерация) среди 15 тыс. американских НПО можно выделить 3 ключевые НПО, которые ведут свою деятельность в отношении Союзного государства [8]:

- Ц Центр анализа европейской политики (СЕРА) - американская неправительственная организация, которая ведет свою деятельность на российско-белорусском направлении. Должность ведущего эксперта в ней занимает бывший главнокомандующий Вооруженными силами США в Европе (EUCOM) Бен Ходжес, который специализируется на российско-белорусском военно-стратегическом сотрудничестве.

Rand Corporation - американская неправительственная организация, крупнейшая «фабрика» военно-политической мысли. Специалистом по российско-белорусским отношениям является аналитик Брюс Макклинток, бывший бригадный генерал армии США, бывший военный атташе посольства США в Москве.

- Атлантический совет - американская неправительственная организация, которая основана при секретариате НАТО. В 2019 г. выступила организатором конференции «Белорусская дилемма для Минска и для Запада». В 2021 г. Атлантический совет выпустил доклад, посвященный стратегии США в отношении Беларуси, рекомендованный администрации Джо Байдена [9]. 
Проведенный анализ деятельности вышеназванных организаций показал, что, с одной стороны, они выполняют функцию информационно-аналитического обеспечения руководства США на российскобелорусском направлении, с другой стороны, они выступают в качестве «институтов мягкой силы США», способных влиять на общественное мнение в Союзном государстве через организацию статусных международных мероприятий, публикацию аналитических докладов и работу в социальных медиа.

Помимо НПО весомую роль в осуществлении мягкой силы США в отношении Союзного государства играют государственные структуры и неправительственные фонды. Среди неправительственных фондов можно выделить Фонд Макартуров (MAF), Фонд «Евразия» (EF), Германский фонд Маршала (GMF), фонд «Открытое общество» Джорджа Copoca, Freedom House, Фонд Форда [8].

Де-юре вышеназванные неправительственные фонды имеют негосударственный статус и официально осуществляют самостоятельное руководство своей деятельностью. Однако де-факто они подчинены иностранным правительствам, министерствам иностранных дел и специальным службам, и являются посредниками в решении внешнеполитических задач.

Проведенный анализ деятельности вышеназванных неправительственных фондов показал, что они имеют двойственную природу. С одной стороны, они выступают, как посредники при финансировании других «институтов мягкой силы», которые специализируются на Союзном государстве, с другой стороны, они сами выступают в качестве «институтов мягкой силы», которые занимаются организацией экспертных мероприятий, форумов, конференций и т.д. на российскобелорусском направлении.

Среди государственных структур США, которые ведут свою деятельность в отношении Союзного государства, можно выделить 4 ведущие организации: Агентство по международному развитию (United States Agency for International Development, USAID) при Госдепартаменте США, Национальный фонд демократии (National Endowment for Democracy, NED), Международный республиканский институт (International Republican Institute, IRI), Национальный демократический институт по международным вопросам (National Democratic Institute for International Affairs, NDI).

Деятельность USAID на территории Республики Беларусь велась с 1999 г. и была прекращена в 2021 г. по инициативе белорус- 
ской стороны (в Российской Федерации Агентству была запрещена деятельность в 2012 г.). На основании данных из открытых источников на финансирование программ USAID выделяется около 1\% всего бюджета США. На работу в Республике Беларусь с 2016 по 2018 гг. ежегодно выделялось от \$19 млн до \$24 млн. В 2018 г. бюджеты остальных государственных структур США составили: Национальный фонд демократии - \$176 млн, Международный республиканский институт - \$87 млн, Национальный демократический институт по международным вопросам - \$141 млн [8].

Помимо вышеназванных «институтов мягкой силы» внешнеполитическое влияние со стороны США в отношении Союзного государства ведется и в информационном пространстве. Современные технологии позволяют оказывать влияние на общественное мнение другого государства без каких-либо цифровых и финансовых следов.

В настоящее время в информационном пространстве Союзного государства функционирует большое количество Telegram и YouTube каналов, сообществ в социальных сетях Facebook и Вконтакте, страниц в Instagram, которые оказывают значительное влияние на общественное мнение и могут приводить к дестабилизации социальнополитической ситуации (на примере событий 2020 г. в Беларуси).

Современные технологии позволяют финансировать деятельность подобных «новых медиа» через операции с криптовалютой, т.е. способом, который не позволяет отследить источник финансирования. Поэтому со стороны правоохранительных органов в отдельных случаях предпринимаются меры о признании подобных «новых медиа» экстремистскими на основании размещаемого контента, но не источника финансирования, который мог бы стать доказательной базой вмешательства иностранного государства во внутренние дела Республики Беларусь и Российской Федерации [10].

На основании проведенного анализа деятельности всех вышеназванных «институтов мягкой силы США» нами предложена авторская классификация современных «институтов мягкой силы США», которые прямым либо косвенным образом оказывают влияние на Союзное государство:

внешнеполитические ведомства и спецслужбы США (примеры: Госдепартамент, USAID, ЦРУ и др.), осуществляющие разведывательную, дипломатическую и иную внешнеполитическую деятельность; 
- неправительственные организации и «мозговые центры» США (Центр анализа европейской политики, Rand Corporation, Атлантический совет), которые решают целый спектр задач, от информационно-аналитического обеспечения политического руководства США до проведения научных исследований;

- неправительственные фонды США (Фонд Макартуров (MAF), Фонд «Евразия» (EF), фонд «Открытое общество» и др.), основной задачей которых является финансовое обеспечение других «институтов мягкой силы»;

- международные медиа организации (Радио «Свобода», «Голос Америки» и др.), выполняющие целый спектр задач, в том числе, влияние на общественное мнение за рубежом.

- «новые медиа», открыто либо негласно спонсируемые США (Telegram и YouTube каналы, сообщества в социальных сетях Facebook и Вконтакте, страницы в Instagram и др.). Выполняют информационные и дезинформационные функции.

С помощью данных «институтов мягкой силы» США могут решать целый спектр стратегических и тактических задач в отношении Союзного государства, от сдерживания до попытки дестабилизации социально-политических систем.

Наиболее ярким примером применения «институтов мягкой силы США» для решения внешнеполитических задач является кампания по срыву экономического проекта России «Северный поток-2». В результате согласованных действий внешнеполитических ведомств США, «новых медиа», международных медиа организаций и НПО строительство «Северного потока-2» столкнулось с множеством трудностей. Среди главных из них можно выделить: создание неблагоприятного образа в мировых медиа («мягкая сила») и введение санкций в отношении ответственных должностных лиц и компаний («жесткая сила»).

Другим ярким примером является принятие в США «Акта о демократии, правах человека и суверенитете Беларуси» и параллельная информационная кампания, направленная на дискредитацию подписания Союзных программ 4 ноября 2021 г. через сеть «новых медиа», НПО и международных медиа организаций [11]. В «Акте о демократии, правах человека и суверенитете Беларуси» закреплены положения, которые не признают включение Беларуси в Союзное государство с Россией и разрешают введение санкций в отношении чиновников Союзного государства. 
На основании проведенного анализа содержания Акта можно сделать прогноз о том, что с 2022 г. США усилят внешнеполитическое влияние на Союзное государство через «институты мягкой силы» с целью противодействия «российскому влиянию» в Беларуси. В результате Союзное государство, оформляющееся как самостоятельный центр силы, столкнется с серьезным вызовом в виде усиленного влияния «мягкой силы США», которое по мере углубления интеграционных процессов будет только нарастать.

Выводы. В результате проведенного исследования было дано определение понятия «мягкая сила», которое ввел в научный оборот американский политолог Джозеф Най в 1990 г. в своей работе «Bound to Lead: The Changing Nature of American Power». В своих исследованиях Джозеф Най разделил мощь государства на две составляющих: «жесткую силу» (совокупную политическую, экономическую и военную мощь государства) и «мягкую силу» (привлекательность государства, его достижения, международный имидж). Нами было выделено два главных отличия «мягкой силы» от «жесткой силы». Вопервых, если «жесткая сила» характеризуется прямым влиянием на другое государство, то «мягкая сила» - косвенным. Во-вторых, «мягкая сила» в отличие от «жесткой» ориентирована на долгосрочное воздействие на другое государство для достижения необходимого результата.

На основании исследований Петера Швейцера нами был рассмотрен исторический аспект «институтов мягкой силы», которых использовали США для победы в «холодной войне». Среди ключевых институтов мы выделили внешнеполитические ведомства и спецслужбы США, научную элиту и выпускников из Гарварда, Принстона, Йелля и других университетов, международные медиа организации и международные неправительственные организации. Были выявлены и проанализированы современные «институты мягкой силы США», с помощью которых США могут решать целый спектр стратегических и тактических задач в отношении Союзного государства, от сдерживания до попытки дестабилизации социально-политических систем. Представлена авторская классификация данных институтов и приведены примеры их влияния на Союзное государство.

Подводя итог, следует отметить, что для эффективного противодействия внешнеполитическому влиянию США «через институты мягкой силы» Союзному государству актуально принять следующие 
тактические меры для выстраивания собственной эффективной системы мягкой силы.

Во-первых, автор выдвигает рекомендацию по принятию в Республике Беларусь Закона «Об иностранных агентах» по аналогии с действующим на территории Российской Федерации законодательством. Юридическое ограничение деятельности иностранных «институтов мягкой силы» является эффективным методом по контролю за деятельностью физических или юридических лиц, которые, являясь резидентом одной страны, действуют в интересах другой страны при отсутствии дипломатического иммунитета.

Во-вторых, автор рекомендует создавать и поддерживать собственные «институты мягкой силы» как на территории Союзного государства, так и за его пределами с целью выстраивания полноценной системы мягкой силы Союзного государства. Одна из первостепенных задач на данном направлении - координация действий внешнеполитических ведомств Союзного государства и «институтов мягкой силы» для проведения согласованных внешнеполитических акций.

В-третьих, актуальным является корректирование системы финансирования «институтов мягкой силы» путем создания союзного фонда поддержки общественных инициатив с возможностью предоставления грантовой поддержки не только юридическим, но и физическим лицам, работающим в сфере «новых медиа».

\section{Библиографические ссылки}

1. The National Security Strategy // Official Gazette [Электронный ресурc]. 2018. URL: https://www.official

gazette.gov.ph/downloads/2018/08aug/20180802-national-security-strategy.pdf. (дата обращения: 20.11.2021).

2. Бурлинова Н.В. Курс общественного дипломата // Российский совет по международным делам. [Электронный ресурс]. 2017. URL: https://russiancouncil.ru/papers/PublicDiplomacyUMM4.pdf (дата обращения: 20.11.2021).

3. Nye J. Bound to lead: The changing nature of American power // Kropf's Poli Sci Grotto. [Электронный ресурс]. 1990. URL: http://www.kropfpolisci.com/exceptionalism.nye.pdf (дата обращения: 20.11.2021).

4. Nye J. Soft Power. The Means to Success in World Politics // Belfer Center [Электронный ресурс]. 2000. URL: https://www.belfercenter.org/sites/default/files/legacy/files/joe_nye_wielding_soft_power.pdf (дата обращения: 20.11.2021).

4. Швейщер П. Победа. Роль тайной стратегии администрации США в распаде Советского Союза и социалистического лагеря // Москва: СП «Авест». 1995. 464 с.

5. Лисичкин В. А., Шелегин Л. А. Третья мировая информационно-психологическая война // Москва: Институт социально-политических исследований АСН. 1999 г. 304 с.

6. Филимонов Г. Ю. Мягкая сила культурной дипломатии США // Москва: РУДН. 2010 г. 212 с.

7. Деятельность НПО в Белоруссии в интересах Запада // Центр стратегических оценок и прогнозов [Электронный ресурс]. 2019. URL: http://csef.ru/ru/politica-i-geopolitica/438/ deyatelnost-npo-v-belorussii-v-interesah-zapada-8976 (дата обращения: 20.11.2021). 
8. Буконкин Д. «Атлантический совет» предложил Байдену изменить политику по Беларуси

// Евразия.Эксперт [Электронный ресурс]. 2021. URL: https://eurasia.expert/atlan ticheskiy-sovet-predlozhil-baydenu-izmenit-politiku-po-belarusi/ (дата обращения: 20.11.2021).

9. Канал и логотип NEXTA признаны экстремистскими материалами // Белта. [Электронный pecypc]. 2020. URL: https://www.belta.by/society/view/kanal-i-logotip-nexta-priznanyekstremistskimi-materialami-411827-2020/ (дата обращения: 20.11.2021).

10. США готовят санкции против Союзного государства Беларуси и России // Евразия.Эксперт [Электронный ресурс]. 2020. URL: https://eurasia.expert/ssha-gotovyat-sanktsiiprotiv-soyuznogo-gosudarstva-belarusi-i-rossii/ (дата обращения: 20.11.2021).

Дата поступления статьи: 25.11.2021.

Автор: Тома Алексей Юрьевич - председатель правления научно-культурного учреждения «Евразийское Партнерство», соискатель кафедры философии и методологии университетского образования РИВШ, toma.alexey@gmail.com.

\title{
SOFT POWER OF THE UNITED STATES AS A TOOL OF FOREIGN POLICY INFLUENCE ON THE UNION STATE
}

\author{
A. Y. TOMA \\ Scientific and cultural institution «Eurasian Partnership», \\ Minsk, Republic of Belarus
}

\begin{abstract}
At present, the Union State, which is taking shape as an independent center of power, is facing a new challenge in the form of US soft power. Analyzing the nature of the geopolitical contradictions in the US - China - Russia triangle, one can predict a new round of confrontation, which will become a serious challenge to the security of the Union State of Belarus and Russia in the long term.

The article is devoted to the analysis of the US soft power in relation to the Union State. The author considers the concepts of "soft power" and "hard power", and their main differences are highlighted. The article identifies and analyzes modern "institutions of US soft power", with the help of which the United States can solve a whole range of strategic and tactical tasks in relation to the Union State. The author's classification of these institutions is presented and examples of their influence on the Union State are given.

As a result of the study, recommendations were proposed for building an effective system of soft power in the Union State of Belarus and Russia. Firstly, the author recommended to adopt the Law "On Foreign Agents" by analogy with the one that is in force on the territory of the Russian Federation. Secondly, the author recommends creating and maintaining one's own "institutions of soft power", both on the territory of the Union State and beyond. Thirdly, it is urgent to adjust the system of financing soft power institutions towards the creation of a union fund to support public initiatives with the ability to provide grant support not only to legal entities, but also to individuals working in the field of "new media".
\end{abstract}


Key words: US foreign policy; soft power; non-governmental organizations; the Union State of Belarus and Russia.

For citations: Toma A. Y. (2021). Myagkaya sila kak instrument vneshnepoliticheskogo vliyaniya na soyuznoye gosudarstvo [Soft power of the United States as a tool of foreign policy influence on the Union State]. In: Actual problems of international relations and global development: collection of scientific papers. Minsk. Vol. 9, p. 263-275. https://doi.org/10.33581/2311-9470-2021-9-263-275

\section{References}

1. The National Security Strategy// Official Gazette [Electronic resource]. 2018. URL: https://www.officialgazette.gov.ph/downloads/2018/08aug/20180802-national-security-strategy .pdf. (Date of access: 20.11.2021). (In Russ.)

2. Burlinova N. V. Kurs obschestvennogo diplomata // Russian International Affairs Council [Electronic resource]. 2017. URL: https://russiancouncil.ru/papers/PublicDiplomacy-UMM4.pdf (Date of access: 20.11.2021). (In Russ.)

3. Nye J. Bound to lead: The changing nature of American power // Kropf's Poli Sci Grotto. [Electronic resource]. 1990. URL: http://www.kropfpolisci.com/exceptionalism.nye.pdf (Date of access: 20.11.2021). (In Russ.)

4. Nye J. Soft Power. The Means to Success in World Politics // Belfer Center. [Electronic resource]. 2000. URL: https://www.belfercenter.org/sites/default/files/legacy/files/joe_nye_wielding _soft_power.pdf (Date of access: 20.11.2021). (In Russ.)

5. Schweitzer. P. Pobeda. Rol' tainoi strategii administacii SSHA v raspade Sovetskogo Souza I socialisticheskogo lagera [Victory. The role of the secret strategy of the US administration in the collapse of the Soviet Union and the socialist camp] // Moscow: JV "Avest". 1995. 464 p. (In Russ.) 6. Lisichkin V. A., Shelegin L. A. Tretiya mirovaya informacionnaya psihologicheskaya voina [The Third World Information and Psychological War] // Moscow: Institute of Socio-Political Research ASN. 1999. 304 p. (In Russ.)

7. Philimonov G. Y. «Myagkaya sila» kulturnoy diplomatii [The "soft power" of US cultural diplomacy]. Moscow: RUDN. 2010. 212 p. (In Russ.)

8. The activities of NGOs in Belarus in the interests of the West // Center for Strategic Assessments and Forecasts. [Electronic resource]. 2019. URL: http://csef.ru/ru/politica-i-geopolitica/438/ deyatelnost-npo-v-belorussii-v-interesah-zapada-8976 (Date of access: 20.11.2021). (In Russ.)

9. Bukonkin D. Atlantic Council suggested Biden to change policy on Belarus // Eurasia.Expert [Electronic resource]. 2021. URL: https://eurasia.expert/atlanticheskiy-sovet-predlozhil-baydenuizmenit-politiku-po-belarusi/ (Date of access: 20.11.2021). (In Russ.)

10. NEXTA Channel and Logo Recognized as Extremist Content // Belta. [Electronic resource]. 2020. URL: https://www.belta.by/society/view/kanal-i-logotip-nexta-priznany-ekstremistskimimaterialami-411827-2020/ (Date of access: 20.11.2021). (In Russ.)

11. The United States is preparing sanctions against the Union State of Belarus and Russia // Eurasia.Expert [Electronic resource]. 2020. URL: https://eurasia.expert/ssha-gotovyat-sanktsii-protivsoyuznogo-gosudarstva-belarusi-i-rossii/ (Date of access: 20.11.2021). (In Russ.)

Received: 26.11 .2021 .

About author: Toma Alexey Yurievich - Chairman of the Board of the Scientific and Cultural Institution «Eurasian Partnership», applicant for the Department of Philosophy and Methodology of University Education, NIHE, toma.alexey@ gmail.com. 